\title{
Knowledge Transfer in the Social Sciences and Humanities (SSH) - Definition, Motivators, Obstacles, and Visions
}

\author{
Daniel Wutti*, Markus Hayden**
}

\begin{abstract}
While knowledge transfer in economic and technical sciences is a matter of frequent research, knowledge transfer in social sciences and humanities (SSH) has not been examined sufficiently in the last few decades. In order to fill the research gap, this paper presents results from a study conducted at an Austrian university. Eighteen scientists were interviewed with regards to a definition, common examples, motivators and obstacles as well as visions of SSH knowledge transfer. Interview transcripts have been analyzed qualitatively. Results were compared with quantitative data derived from the research documentation system of the university.

A comprehensive definition of SSH knowledge transfer is presented. Motivators turned out to be closely linked to perceived personal and civic duties. Obstacles were described as being attributable to a focus on 'science to science' achievements within the scientific community.
\end{abstract}

Key words: Knowledge Transfer, Social Sciences, Humanities, Expert Interviews, Qualitative Content Analysis, University

\footnotetext{
* Institut für Mehrsprachigkeit und Interkulturelle Bildung, Pädagogische Hochschule Kärnten - Viktor Frankl Hochschule; daniel.wutti@ph-kaernten.ac.at

** Alpen-Adria-Universitä Klagenfurt; markus.hayden@aau.at
} 


\section{Introduction}

Apart from teaching and researching, universities are required to complete other tasks as well. This so called 'third mission' includes the transfer of knowledge to non-academic communities (Trencher et al. 2014). However, scientific research on this special field of a university's responsibility can be described as being incomplete (Olmos-Peñuela, Castro-Martínez, and D'Este 2014). On the one hand, many different scientific papers exist on the transfer of knowledge from universities into the economy (for an overview, see for example Geuna and Muscio 2009). These pieces of research mainly focus on the commercialization of academic knowledge and teaching as well as on links between university and industry. On the other hand, however, other elements of university knowledge transfer are studied insufficiently. In particular, transfer of knowledge within the different disciplines of the social sciences and humanities (SSH) has hardly been examined (Olmos-Peñuela, Benneworth, and Castro-Martinez 2014). There is not even a consistent nomenclature that has gained acceptance in scientific research. Common examples include for example 'knowledge transfer', 'knowledge exchange', 'knowledge mobilization' or 'knowledge translation and transfer' (Phipps, Jensen, and Myers 2012).

Current theories to explain this imbalance within scientific literature state that research output in the SSH is more difficult to evaluate than in science, technology, engineering, and mathematics (STEM) (Olmos-Peñuela, Benneworth, and Castro-Martinez 2014). It is important to keep in mind that popular benchmarks, for example the number of patents or university spin-offs, are unreliable indicators for social benefits (OlmosPeñuela, Castro-Martínez, and D'Este 2014).

Another factor that influences the research of SSH knowledge transfer negatively is the lack of data material. The scientific output of universities is usually described by specific factors referring to achievements within the scientific community, which can be defined as 'science to science'. Knowledge transfer in the SSH is typically linked to the fields of communication with practitioners (also known as 'science to professionals') and communication with the public, or, in other words, 'science to public'. These issues have received significantly less academic recognition and there is hardly any data available (Olmos-Peñuela, Castro-Martínez, and Manjarrés-Henríquez 2010).

As a matter of fact, the promotion of knowledge transfer should be a serious goal for the SSH. Especially in the context of global challenges, the SSH play an important role in the search for sustainable answers. Researchers are encouraged to promote the inclusion of their study results into professional practice, public policy, and legislation (Van Langenhove 2012). To gain influential attention, both scientists and universities have to commit themselves to knowledge transfer (Nisbet and Mooney 2007). In this regard, the involvement in open science and open access of research results (European Commission 2016a, 2016b; Wolpert 2013) should be mentioned as a topic of particular importance. Examples of these approaches are defined by the Budapest Open Access Initiative (http://www.budapestopenaccessinitiative.org/read) and the Berlin Declaration on 
Open Access to Knowledge in the Sciences and Humanities (http://openaccess.mpg.de/Ber liner-Erklaerung). They promote the provision of online access to scientific information free of charge. It enables people both inside and outside of academic environments to gain information on each academic discipline. Researchers and institutions may reuse this information for further research and study (European Commission 2016a, 2016b). Large parts of university research are funded publicly, therefore, the salaries of many researchers are paid with tax money. Hence, free access to research results should be taken for granted (Wolpert 2013).

To summarize, knowledge transfer in the SSH can be described as being important, but is not supported nor examined enough. In Austria, the Federal Ministry of Science, Research and Economy approached this problem by installing three knowledge transfer centers in order to link the country's southern, eastern and western universities. Although the initiative primarily focuses on promoting knowledge transfer between science and economy to foster economic benefit, a certain financial support is dedicated to illuminate and strengthen SSH knowledge transfer. The present pilot study was conducted to provide a basis for further examinations of knowledge transfer in the SSH.

Firstly, we strived to find a comprehensive definition of knowledge transfer in the SSH as well as common examples thereof. To minimize any distortion of subject's answers, we intentionally asked only open questions and did not provide any examples, neither from previous research, nor from other interviews. Next, we asked scientists about their experiences with knowledge transfer in the SSH, especially regarding motivators and drawbacks. Thirdly, we asked whether knowledge transfer in the SSH is appreciated or not. We then explored scientists' further visions and perspectives for SSH knowledge transfer. Finally, we compared the reported subjective experiences with the output of the university.

\section{Sample}

In the present study, we strived to examine the experiences and attitudes of researchers in the field of SSH. In order to fulfill this task, we used a Typical Case Sampling strategy (Teddlie and $\mathrm{Yu}$ 2007) to approach content-related representative cases. This technique aims at finding interviewees that can be described as being typical representatives of the field of study. As the spectrum of 'typical SSH researchers' includes different scientific disciplines, different levels of academic career, as well as sex and age, we sought to achieve a broad distribution of interviewees. Requests for participation were sent to all the departments of the two faculties that are mainly engaged in SSH research, namely the Faculty of Humanities and the Faculty of Interdisciplinary Studies. With the exception of three departments, at least one scientist from each department agreed to participate in the study. The final sample comprised eighteen researchers, all of whom were employed by the university during the study. Subjects were recruited between December 2014 
and July 2015. Participants, as shown in table 1, were scientists of different scientific disciplines and were at different levels of their academic career.

Academic Level

\begin{tabular}{lrrr}
\hline & Male & Female & Total \\
\hline Predoctoral & & 1 & 1 \\
Postdoctoral & 4 & 3 & 7 \\
Habilitation Completed & 6 & 4 & 10 \\
\hline Total & 10 & 8 & 18 \\
\hline Scientific Disciplines & & \\
\hline Business Studies & & \\
Cultural Anthropology & & 1 \\
Educational Science & 3 \\
English Studies & & 1 \\
Geography & & 1 \\
German Studies & & 2 \\
History & & 1 \\
Media and Communication Science & & 3 \\
Psychology & & 2 \\
Romance Studies & & 1 \\
Slavonic Studies & & 2 \\
\hline Total & & 18 \\
\hline
\end{tabular}

Table 1: Study sample

\section{Methods and design}

In this study we used a mixed method approach (Creswell and Plano Clark 2011) to intentionally combine both qualitative and quantitative methods. This strategy was chosen, as we aimed to link subjective experiences with objective key performance indicators in order to determine whether experiences were biased by selective perception (Ditto and Lopez 1992). We applied qualitative methods to explore the subjective experiences of researchers within the SSH and quantitative methods to compare these experiences with the academic output of the university.

In order to collect different views from experts in the field of SSH we used semistructured expert interviews (Meuser and Nagel 2009). These were afterwards transcribed and analyzed qualitatively. For the analysis, all transcripts were imported into the online-tool QCAmap (www.qcamap.org). Afterwards, we used the method of qualitative content analysis (Mayring 2014) to inductively form qualitative categories. By means of qualitative content analysis, qualitative data material can systematically be reduced at an early stage of the analysis. Both inductive and deductive procedures may 
be applied to form qualitative categories that can furthermore be quantified and compared. This strategy seemed to be most appropriate as more than thirteen hours of audio recordings led to 232,311 transcribed characters.

All the interviews were independently coded by the authors. After the first half of the process, coding schemata were discussed and compared to create a consistent pattern of categories. On the basis of this category system, all the transcripts were independently rated as a whole.

For the last research question, we also analyzed quantitative data that was obtained from the research documentation system of the university (Forschungsdokumentation; FoDok). This software was designed to fulfil the responsibility of recording all the scientific achievements of the university. Recordings are entered by the scientists themselves, but are reviewed by trained professionals. All entries in FoDok are categorized by the target audience ('science to science'; 'science to professionals'; 'science to public'). Therefore, the relationship between academically and non-academically focused outputs can be outlined.

Data from the two faculties that are mainly engaged in SSH research (the Faculty of Humanities and the Faculty of Interdisciplinary Studies), was extracted from FoDok, in order to obtain key performance indicators for both science to science and knowledge transfer achievements. These indicators were later used as reference value in the comparison between subjective experiences and objective outcome measures.

\section{Results}

The following section displays the categories of the qualitative content analysis arranged in the order of the research questions. In the last part, qualitative results were compared with the academic output of the university where all participants were employed at the time the study took place.

\subsection{A proposal for a definition of SSH knowledge transfer}

The topic of SSH knowledge transfer seemed quite new to most subjects, although in most interviews subjects quickly found themselves in medias res. Contributions from subjects assigned to this category range from making "theoretical knowledge usable" and "raising consciousness about topics" to "working on the borders of different spheres of society" and "transferring knowledge from science to practice". Subjects argued that universities are established and financed by societies, and therefore should work on making their knowledge achievements visible, understandable, and graspable for the broader public. It was noticeable that people who were already working and engaging in fields close to practice mentioned and defined their work specifically as knowledge transfer. 
This was often in a context where they perceived that they had not received any appreciation for this kind of work. Another result was that technical knowledge transfer, or knowledge transfer in the field of STEM sciences, is easier to define and to measure. It was also clear for the interviewed persons that SSH knowledge transfer should not be equaled to transfer within the scientific community. Science communication was named as a specific field of knowledge transfer, but not the only field. SSH knowledge transfer was also referred to as experiencing, sharing, and researching together with practitioners, as a specific strategy for researchers to widen their research. A clear distinction to primarily profit-orientated knowledge transfer was mentioned as well.

\subsection{Examples of SSH knowledge transfer}

Several specific examples of SSH knowledge transfer were identified by the subjects. Qualitative content analysis exposed four main groups:

- Cooperation with the media The interviewed persons mentioned science communication completed by themselves. They produce media contributions on their own: some participate in radio and television shows, others produce radio programs on specific topics. Scientists mentioned that they write and respond to readers' letters of national as well as regional newspapers. They act on requests by the media, and give interviews about their scientific work.

- Cooperation and work with society / the public

Subjects outlined a variety of events they had organized themselves that were dedicated to knowledge transfer. They organize talks and presentations beyond the university, often in cultural and political spheres. They are invited to moderate events in their field of expertise as scientists. They also participate as experts in panel discussions with representatives of other spheres of society. Scientists cooperate with organizations, clubs, and associations for the sake of knowledge transfer. They conduct research on questions relevant to society and to public policy, and are engaged in making their results visible.

- Transfer with practice

The interviewed scientists outlined their cooperation with practicing professionals as an important factor of SSH knowledge transfer. Results show that SSH researchers often work closely with experts working within similar scientific fields. Subjects see a close relationship with professionals as an advantage because they can then link their scientific work to requirements of practical fields. In communication with specialists, the subjects can determine the current demands of practical fields, reflect on them scientifically, and transfer those results back to 
the experts. A cycle of advantages for the representatives of different spheres was identified by the subjects.

Scientists organize and participate in workshops both made for and made by experts in practical fields. They present at conferences, and at meetings of professionals. Publications are being (re)written and scientists (co)work on certain information materials for professional practice.

- Teaching

Surprisingly, for the authors of this article, a number of scientists named their university teaching as SSH knowledge transfer. A number of engaged scholars work on innovative concepts for lectures and allow students to gain practical experience by working for professionals. Scientists prepare content for their students based on relevant questions for society and for the public. They send their students to different fields of society to combine theory with practice. Engaged scholars foster critical understanding and observation of societal trends in practical fields. Lessons and seminars with high references to practice were named by the scientists, who mentioned them as an important factor of their SSH knowledge transfer work.

\subsection{Motivational factors and reasons for SSH knowledge transfer}

The interviewed scientists mentioned the feeling of a certain personal obligation for knowledge transfer. Knowledge and scientific results should neither be solely collected and saved by individuals, nor should they be just stored within a scientific community. On the contrary, they should be accessible to the broader public. Scientific findings should widen the consciousness of individuals in a society and lead to (social) enhancement. A second 'obligation' mentioned by the subjects was a societal obligation. They felt that SSH knowledge transfer should be forced as a justification for the economic and financial costs, since Austrian universities are financed by the public sector.

Some mentioned their idea of SSH knowledge transfer as empowerment of the region. This could be especially important for small and marginalized regions such as Carinthia, where the subjects are employed. Ideas to create enthusiasm and excitement for research and science, to reach people, touch them, delight and inspire them, were mentioned as well. Moreover, SSH knowledge transfer was identified as a strategy for expanding one's audience. Establishing and raising public awareness of a certain topic could also be achieved through SSH knowledge transfer.

The subjects saw a double-sided benefit in SSH knowledge transfer: subjects gained new insights and were able to facilitate them simultaneously. SSH knowledge transfer in this sense means fostering exchange through mutual development of knowledge. Science can improve practice while practice can improve science. A certain number of scientists mentioned that their motivation in SSH knowledge transfer is founded in their own roots in practice; coming from professional spheres or from fields close to practice, they 
are motivated to keep these ties. They have precise ideas how to benefit from knowledge transfer.

Extrinsic motivation such as knowledge transfer for one's own reputation, for one's curriculum vitae, or financial interests were mentioned en passant by the subjects.

\subsection{Perception of the appreciation of SSH knowledge transfer}

Signs of appreciation of SSH knowledge transfer include scientific topics discussed in public, research results helping to improve practice, as well as positive responses to fields of practice. Appreciation is also granted by certain colleagues. Simultaneously, subjects expressed their feeling that appreciation could not be found within the scientific community. What counts towards a scientific career and what leads to reputation are 'science to science' activities. These activities can be expressed by key performance indicators and classification numbers. Subjects mentioned a pressure to manage and achieve high performances. Bureaucracy forces scientists to report performance records. According to the subjects' opinion, this seems to be a new tendency in the scientific community. Some reported that they wished to work more in SSH knowledge transfer, but are hardly able to manage the demands in the field of 'science to science'. They reported a feeling of being measured in numbers as well as a pressure to research in mainstream directions. A certain governance of science was assumed by some subjects.

Negative aspects of SSH knowledge transfer are that scientific results and achievements are not necessarily accepted positively by society. High-quality knowledge transfer needs adequate funding and is costly in terms of time and energy.

\subsection{Visions and proposals}

Subjects reported their vision of SSH knowledge transfer being accepted in the scientific community. This, however, should focus more on its educational mandate. Universities should support events in SSH knowledge transfer and cooperations with the broader public. Financial funding for knowledge transfer should be installed sustainably. Incentive systems for knowledge transfer should be professionalized. Subjects wanted networks and platforms for engaged people to be established. SSH knowledge transfer was also mentioned as a potential for creativity, which, in turn, can be very well used in SSH science.

Scientists are worried that bureaucracy might increase as soon as SSH knowledge transfer is accepted within the scientific community and within the university system to a larger extent. Subjects argued that this is to be avoided. SSH knowledge transfer should not lose its creative potential. Regarding the measurement of knowledge transfer in terms of key performance indicators and classification numbers, concerns were raised that these might lead to standardization. At the same time, subjects mentioned the idea of new categories for SSH knowledge transfer in performance records to foster its acceptance. 
The scientific community should re-balance its values. Research that includes knowledge transfer should be promoted. SSH knowledge transfer should be represented in its whole range, as there is a wide spectrum of activities. It was mentioned that the social sciences and humanities often seem to have difficulties explaining its costs to taxpayers and decision makers. Subjects argued that knowledge transfer, as a necessary interface to society, could help here, if there were strategies promoting it.

\subsection{Research output}

In the final step, we analyzed data from the FoDok and compared these results with the qualitative categories derived from the interviews.

Quantitative data was obtained from the two faculties that are mainly engaged in SSH research (the Faculty of Humanities and the Faculty of Interdisciplinary Studies). Furthermore, we focused only on three research categories: publications (academic and related publications, therefore excluding newspaper articles, blogposts, etc.), lectures, and events. Research projects, the fourth largest category, were excluded, because projects that started before the year 2014 were not assigned to different target audiences and can therefore not be categorized as being academically or non-academically focused.

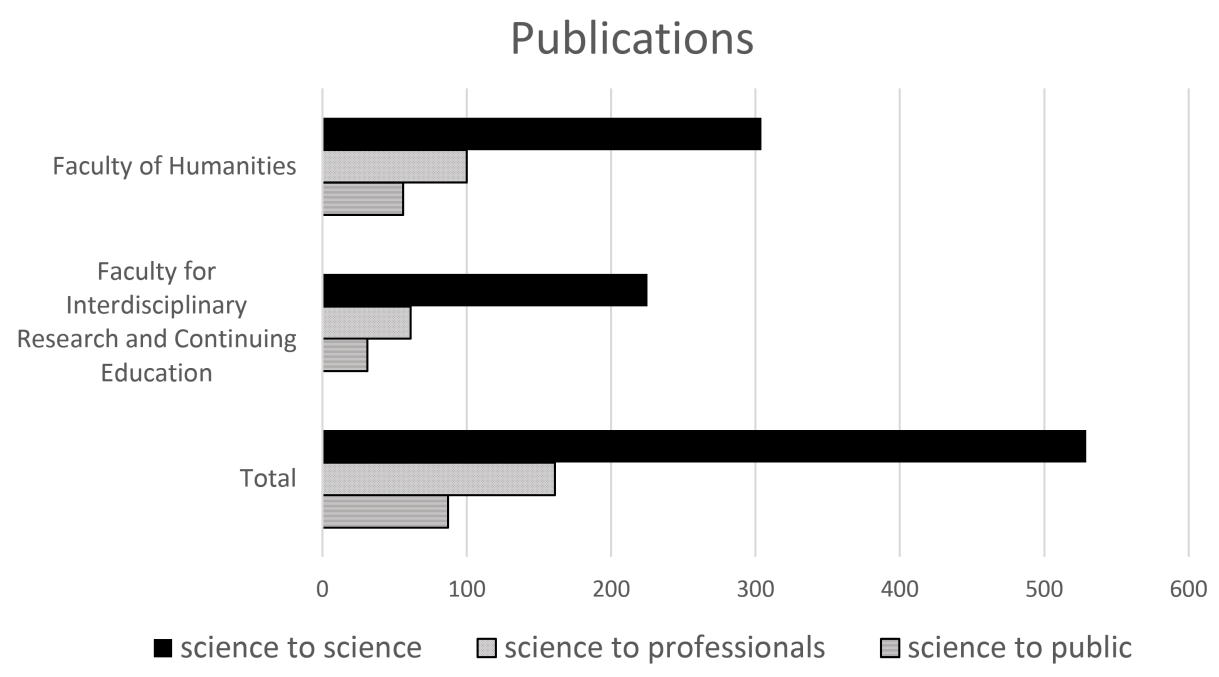

Figure 1: Publications of the Faculty of Humanities and the Faculty of Interdisciplinary Studies of the AAU in 2014

As shown in figure 1 and 2, both in publications and in lectures, a great gap can be observed between the three categories. The vast majority of records are categorized as having a 'science to science' focus. There are somewhat more 'science to professionals' records than 'science to public' ones. Both knowledge transfer categories combined represent about half the number of 'science to science' publications and lectures. 


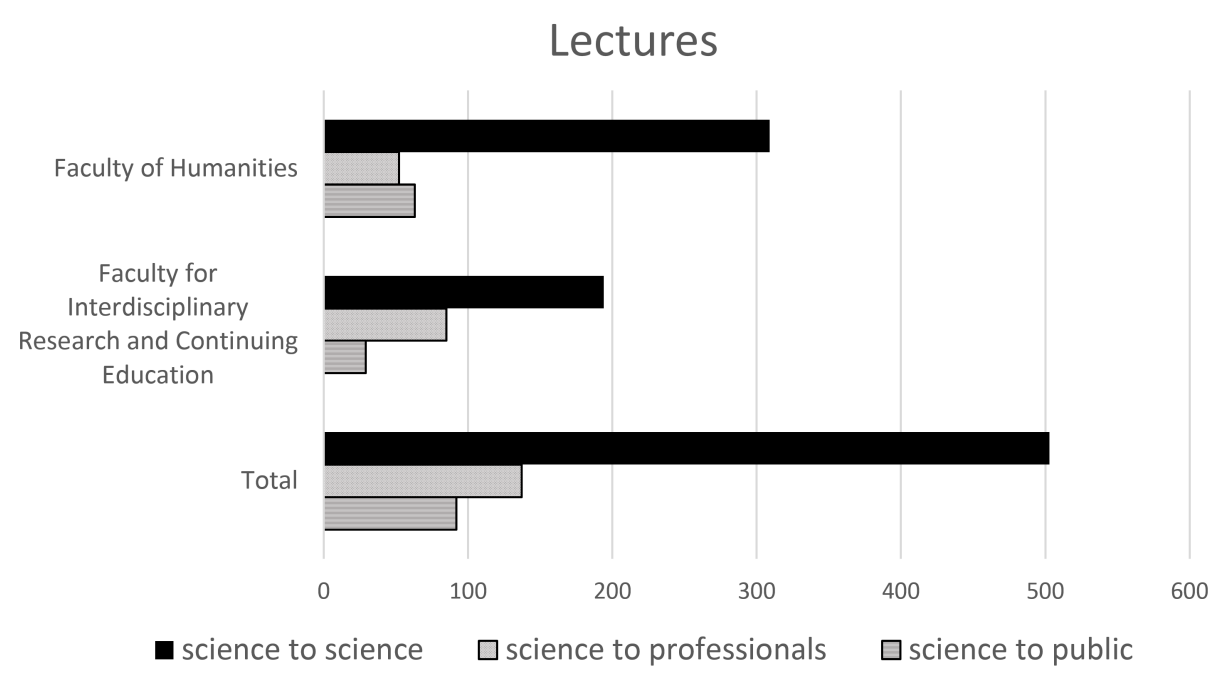

Figure 2: Lectures of the Faculty of Humanities and the Faculty of Interdisciplinary Studies of the AAU in 2014

Figure 3 reveals that the gap between 'science to science' activities and knowledge transfer categories turned out to be noticeably smaller in events. There were about as many 'science to professionals' and 'science to public' entries in FoDok combined as 'science to science' achievements.



घcience to science $\quad \square$ science to professionals $\quad \square$ science to public

Figure 3: Events of the Faculty of Humanities and the Faculty of Interdisciplinary Studies of the AAU in 2014 


\section{Discussion}

The purpose of this paper was to provide a basis for further research and promotion of knowledge transfer in the SSH. First of all, we tried to find a comprehensive definition, since nomenclature has not been standardized yet (Phipps, Jensen, and Myers 2012). Based on our results, we propose the following definition:

Knowledge transfer in the social sciences and humanities implies transmission of scientifically based knowledge to practice and/or the public and vice versa. Its purpose includes the raising of consciousness. SSH knowledge transfer has no primarily economic aim, is distinct to the term of knowledge transfer in technical or economic spheres and is also distinct to knowledge transfer within the scientific community. An important part of SSH knowledge transfer includes science communication.

Subjects named a high number of specific examples of their engagement in SSH knowledge transfer. The spectrum of mentioned activities is broad and creative. It is obvious that certain scientific disciplines focus on different types of knowledge transfer in the SSH. Examples given by the scientists are consistently transdisciplinary and transinstitutional, which goes in line with other research results (Olmos-Peñuela, CastroMartínez, and D'Este 2014). Interconnection with educationalists in educational sciences and exhibitions in historical sciences could be named as two specific examples derived from the interviews. Results clearly show that scholars engaged in SSH knowledge transfer use the exchange with professionals to transfer new and innovative topics from practice into the scientific community.

Most of the scientists we interviewed mentioned science communication as an important part of SSH knowledge transfer. Media relations and collaboration with journalists were examples frequently stated by the subjects. This consideration is of particular interest, as science communication is an imperative part of scientific business (Nisbet and Mooney 2007). Furthermore, research has demonstrated that television, newspapers, and radio are the primary sources for scientific information most commonly cited by the general public (European Commission 2013). Because knowledge is being transmitted to the public more and more often through less mediated sources like mass media and the internet, academically verified knowledge transfer has become even more important (Besley and Tanner 2011). As a matter of course, many universities and research institutions have special departments for science communication and public relations that take care of most of these duties. However, researchers should keep in mind that the general public label scientists to be the best qualified to explain research results (European Commission 2013).

Our results indicate that scientists working in SSH fields often research on questions relevant to society and public policy. They are engaged in making the results available. Their motivation in knowledge transfer is intrinsic rather than extrinsic in terms of 
financial interests or economic benefit. Similar results were obtained by Olmos-Peñuela, Castro-Martínez, and D'Este (2014). SSH scientists can be driven by the idea of an improvement of social conditions. SSH knowledge transfer appears to be a strategy to approach this aim.

Scientists working in SSH fields assign an important role to knowledge transfer. However, their idea is that these activities are not appreciated by the scientific community. In times when it is becoming increasingly necessary for universities and researchers to utilize scientific work and to justify their economic and financial costs to taxpayers and decision makers (Landry, Amara, and Lamari 2001), SSH knowledge transfer should be considered as an important factor which takes these concerns into account. Our results link the perceived relevance of social sciences and humanities in society directly to knowledge transfer. With an increase of (high-quality) knowledge transfer, the SSH might gain a greater standing. According to our results, the scientific community is far away from this idea. Older scientists mentioned that knowledge transfer, in a sense of exchange between science and practice, was more developed decades ago. Concurrent bureaucratic challenges as well as the increasing pressure on scientists to achieve a high level of performance have negative impacts on this field. It seems paradoxical that political decision makers (and therefore universities as well) choose to force scholars to produce outputs that can be expressed by key performance indicators and classification numbers rather than to strengthen knowledge transfer and the practical use of research results for society.

Despite the intrinsic motivation of researchers and the idealistic goals attributed to knowledge transfer in the SSH, subjects did not mention the topic of open access or open science on their own. Although the topic is of great importance in the field of knowledge transfer (European Commission 2016b), it does not seem to be directly linked. However, it is important to remember that we intentionally did not mention these issues during the interviews. Even topics of particular interest for knowledge transfer were not addressed by the interviewers in order to achieve unbiased information. Our research results concerning this field suggest that open access and open science have, so far, not been made popular enough to the scientists who took part in the study. It also implies that more research should be conducted within this field.

Another specific result of the qualitative analysis was that obstacles to SSH knowledge transfer were often mentioned in combination with a perceived pressure to manage and achieve high levels of performance in scientific records. This focus on 'science to science' achievements seemed to be a more recent tendency in the scientific community. Besides concurrent demands on scholars, knowledge transfer is often given less importance as it neither leads to an improved scientific reputation nor benefits an academic career.

According to our results, the following strategies should be considered to promote knowledge transfer in the social sciences and humanities: Firstly, the scientific community should rebalance its values and focus more on its educational mandate. Secondly, incentive systems should be professionalized and financial funding for knowledge trans- 
fer should be installed in a sustainable manner. Finally, visible networks and platforms of engaged people should be created.

The comparison of qualitative categories with quantitative data derived from FoDok showed that knowledge transfer activities are noticeably less reported and entered into FoDok. In 2014, there were about twice as many 'science to science' publications than 'science to professionals' and 'science to public' entries combined. About the same proportion also applies to lectures. Although there was a difference between the categories in events, the gap between knowledge transfer and 'science to science' activities was smaller. There were about as many 'science to science' events as 'science to professionals' and 'science to public' entries combined. For the Faculty of Humanities, the ratio was inverted with as many 'science to science' events as 'science to professionals' and half the number of 'science to public' activities, respectively. Nevertheless, it is important to remark that the total number of events is significantly smaller than the number of publications as well as the number of lectures. Therefore, it is a debatable point, whether results from this category can be perceived as reliable. The most probable explanation for the observable overall difference between 'science to science' activities and the knowledge transfer categories refers to the performance agreements that universities have to fulfill. In Austria's higher education system, universities negotiate performance agreements with the responsible ministry. These agreements determine the academic output for each year and usually contain targets for the number of 'science to science' achievements, but not for knowledge transfer. It is therefore comprehensible that scientists are forced to focus on 'science to science' outputs. However, a change in this strategy is noticeable since the university's latest performance agreement contains targets for knowledge transfer.

Although results from the analysis of FoDok data do seem to give a negative expression of the knowledge transfer output, we point out that teaching and researching are the main duties of academic business (Trencher et al. 2014). Therefore, a gap between 'science to science' and the other two categories is fundamentally justified. Yet an increase in the amount of 'science to professionals' and 'science to public' activities is to be targeted (Landry, Amara, and Lamari 2001).

Our research faced some limitations as it was designed as a pilot study. Firstly, it compromised only a small sample of scientists. Furthermore, all the subjects were employed at the same university and quantitative data was also assessed from only one university. Therefore, it is doubtful whether all the results can be generalized. Nevertheless, two implications can clearly be derived from the study: First, SSH scientists seem to struggle to promote knowledge transfer while simultaneously fulfilling the demands of high quality research. As long as researchers are forced to produce increasing amounts of 'science to science' achievements, opportunities to engage in knowledge transfer will be diminished. Secondly, as common key performance indicators, like the number of patents, or university spin-offs, are not suitable for the SSH, new strategies for the assessment of universities' knowledge transfer activities should be developed. 
Based on the results of the present study, a nationwide quantitative investigation is currently being conducted, in order to produce further research results that can be generalized (Hayden and Wutti, in prep.)

\section{Conclusion}

Qualitative results suggest a definition of knowledge transfer in the SSH that includes the following criteria:

- Transmission of academic knowledge into professional practice and public spheres and vice versa

- Not primarily profit-oriented, but rather based on an idea of raising consciousness

- Distinct from knowledge transfer in technological sciences and economics

- Distinct from transfer of knowledge within the scientific community

- Including scientific communication

Furthermore, we could demonstrate that motivators for knowledge transfer in the SSH are closely linked to personal and civic duties. On the other hand, obstacles were described as being system-related and closely linked to the focus on 'science to science'. This focus could be verified when analyzing the academic output of the university where the study took place. Although it is important to keep in mind that knowledge transfer is not the main task universities must fulfill, SSH knowledge transfer is to be appreciated as an important part of university business. Furthermore, it should be considered a boost for creativity, and consequently even for enhancing scientific output.

We recommend further research in the field of SSH knowledge transfer with larger samples from different universities and regions.

\section{References}

Besley, J. C., and A. H. Tanner. 2011. "What Science Communication Scholars Think About Training Scientists to Communicate.” Science Communication 33 (2): 239-63. doi:10.1177/1075 547010386972.

Creswell, John W., and Vicki L. Plano Clark. 2011. Designing and Conducting Mixed Methods Research. 2nd ed. Los Angeles: Sage Publications Ltd.

Ditto, Peter H., and David F. Lopez. 1992. "Motivated Skepticism: Use of Differential Decision Criteria for Preferred and Nonpreferred Conclusions." Journal of Personality and Social Psychology 63 (4): 568-84. doi:10.1037//0022-3514.63.4.568.

European Commission. 2013. "Spezial Eurobarometer 401 - Responsible Research and Innovation (RRI), Science and Technology.” http://ec.europa.eu/public_opinion/archives/ebs/ebs_401_ en.pdf. 
European Commission. 2016a. "Guidelines on Open Access to Scientific Publications and Research Data in Horizon 2020.” https://ec.europa.eu/research/participants/data/ref/h2020/gra nts_manual/hi/oa_pilot/h2020-hi-oa-pilot-guide_en.pdf.

European Commission. 2016b. “Open Innovation, Open Science, Open to the World.” Brussels. doi:10.2777/061652.

Geuna, Aldo, and Alessandro Muscio. 2009. "The Governance of University Knowledge Transfer: A Critical Review of the Literature.” Minerva 47 (1): 93-114.

Hayden, Markus, and Daniel Wutti. n.d. "Quantitative Research on Knowledge Transfer in the Social Sciences and Humanities (SSH).”

Landry, Réjean, Nabil Amara, and Moktar Lamari. 2001. "Climbing the Ladder of Research Utilization. Evidence from Social Science Research.” Science Communication 22 (4): 396-422.

Langenhove, Luk Van. 2012. "Global Issues: Make Social Sciences Relevant." Nature 484 (7395): 442-442. doi:10.1038/484442a.

Mayring, Philipp. 2014. "Qualitative Content Analysis: Theoretical Foundation, Basic Procedures and Software Solution.” http://nbn-resolving.de/urn:nbn:de:0168-ssoar-395173.

Meuser, Michael, and Ulrike Nagel. 2009. "The Expert Interview and Changes in Knowledge Production.” In Interviewing Experts, edited by Alexander Bogner, Beate Littig, and Wolfgang Menz, 17-42. London: Palgrave Macmillan UK. doi:10.1057/9780230244276_2.

Nisbet, M. C., and C. Mooney. 2007. "Framing Science.” Science 316 (5821): 56. doi:10.1126/scien ce. 1142030 .

Olmos-Peñuela, Julia, Paul Benneworth, and Elena Castro-Martinez. 2014. "Are 'STEM from Mars and SSH from Venus'?: Challenging Disciplinary Stereotypes of Research's Social Value.” Science and Public Policy 41 (3): 384-400. doi:10.1093/scipol/sct071.

Olmos-Peñuela, Julia, Elena Castro-Martínez, and Pablo D’Este. 2014. “Knowledge Transfer Activities in Social Sciences and Humanities: Explaining the Interactions of Research Groups with Non-Academic Agents." Research Policy 43 (4): 696-706. doi:10.1016/j.respol.2013.12.004.

Olmos-Peñuela, Julia, Elena Castro-Martínez, and Liney Adriana Manjarrés-Henríquez. 2010. "Knowledge Transfer In Humanities And Social Science Research Groups: The Relevance Of Organizational Factors.” Ingenio Working Paper Series 2010/15.

Phipps, David J., Krista E. Jensen, and Gary J. Myers. 2012. "Applying Social Sciences Research for Public Benefit Using Knowledge Mobilization and Social Media.” In Theoretical and Methodological Approaches to Social Sciences and Knowledge Management, edited by Asunción Lopez-Varela, 167-96. InTech. doi:10.5772/37533.

Teddlie, C., and F. Yu. 2007. "Mixed Methods Sampling: A Typology With Examples." Journal of Mixed Methods Research 1 (1): 77-100. doi:10.1177/2345678906292430.

Trencher, Gregory, Masaru Yarime, Kes B. McCormick, Christopher N H Doll, and Steven B. Kraines. 2014. "Beyond the Third Mission: Exploring the Emerging University Function of Co-Creation for Sustainability." Science and Public Policy 41 (2): 151-79. doi:10.1093/scipol/sc t044.

Wolpert, Ann J. 2013. "For the Sake of Inquiry and Knowledge - The Inevitability of Open Access.” New England Journal of Medicine 368 (9): 785-87. doi:10.1056/NEJMp1211410. 